\section{Effects of cholesterol levels on outcomes of out-of-hospital cardiac arrest: a cross-sectional study}

\author{
Jong Hwan Kim ${ }^{1}$, Dae Han Wi², Jun Hee Lee ${ }^{2}$, Hyung Jun Song ${ }^{1}$, \\ Sang Do Shin ${ }^{3}$, Young Sun $\mathrm{Ro}^{4}$, Kwang-Ho Bae ${ }^{5}$ \\ 'Department of Emergency Medicine, Wonkwang University Sanbon Hospital, Gunpo, Korea \\ ${ }^{2}$ Department of Emergency Medicine, Wonkwang University Sanbon Hospital, Wonkwang University School \\ of Medicine, Gunpo, Korea \\ ${ }^{3}$ Department of Emergency Medicine, Seoul National University Hospital, Seoul National University College \\ of Medicine, Seoul, Korea \\ ${ }^{4}$ Laboratory of Emergency Medical Services, Seoul National University Hospital Biomedical Research \\ Institute, Seoul, Korea \\ ${ }^{5}$ Mibyeong Research Center, Korea Institute of Oriental Medicine, Daejeon, Korea
}

Objective High cholesterol level is a risk factor for coronary artery disease, and coronary artery disease is a major risk factor for out-of-hospital cardiac arrest (OHCA). However, the effect of cholesterol level on outcomes of OHCA has been poorly studied. This study aimed to determine the effect of cholesterol level on outcomes of OHCA.

Methods This cross-sectional study used the CAPTURES (Cardiac Arrest Pursuit Trial with Unique Registration and Epidemiologic Surveillance) project database in Korea. Multivariable conditional logistic regression analysis was performed to estimate the effect of cholesterol level on outcomes in OHCA.

Results In all, 584 cases of OHCA were analyzed; those with cholesterol levels $<120 \mathrm{mg} / \mathrm{dL}$ were classified as having low total cholesterol (TC) $(n=197)$, those with levels ranging from 120-199 mg/dL as middle TC $(n=322)$, and those with $\geq 200 \mathrm{mg} / \mathrm{dL}$ as high TC $(n=65)$. Compared to low TC, more patients with middle TC and high TC survived to discharge $(9.1 \%$ vs. $22.0 \%$ and $26.2 \%$, respectively, $P=0.001$ ). The good cerebral performance category also increased in that order ( $4.1 \%$ vs. $14.6 \%$ and $23.1 \%$, respectively, $\mathrm{P} \leq 0.001)$. Comparing middle TC and high TC with low TC, adjusted odds ratios (95\% confidence intervals) were 1.97 (1.06 to 3.64 ) and 2.53 (1.08 to 5.92) for survival to discharge, respectively, and 2.53 (1.07 to 5.98) and 4.73 (1.63 to 13.71) for good neurological recovery, respectively.

Conclusion Higher cholesterol is associated with better outcomes in OHCA; cholesterol level is a good predictor of outcomes of OHCA.

Keywords Heart arrest; Cholesterol; Outcome; Cardiac Arrest Pursuit Trial with Unique Registration and Epidemiologic Surveillance
eISSN: 2383-4625

Received: 14 July 2018

Revised: 10 September 2018

Accepted: 12 October 2018

Correspondence to: Dae Han Wi Department of Emergency Medicine, Wonkwang University Sanbon Hospital, Wonkwang University School of Medicine, 321 Sanbon-ro, Gunpo 15865, Korea

E-mail: great@wku.ac.kr ORCID

http://orcid.org/0000-0002-5658-1137

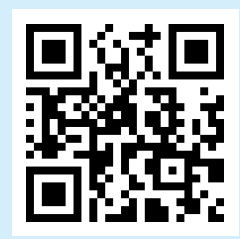

How to cite this article:

Kim JH, Wi DH, Lee JH, Song HJ, Shin SD, Ro YS, Bae KH. Effects of cholesterol levels on outcomes of out-of-hospital cardiac arrest: a cross-sectional study. Clin Exp Emerg Med 2019;6(3):242-249.

This is an Open Access article distributed under the terms of the Creative Commons Attribution Non-Commercial License (http:// creativecommons.org/licenses/by-nc/4.0/). 


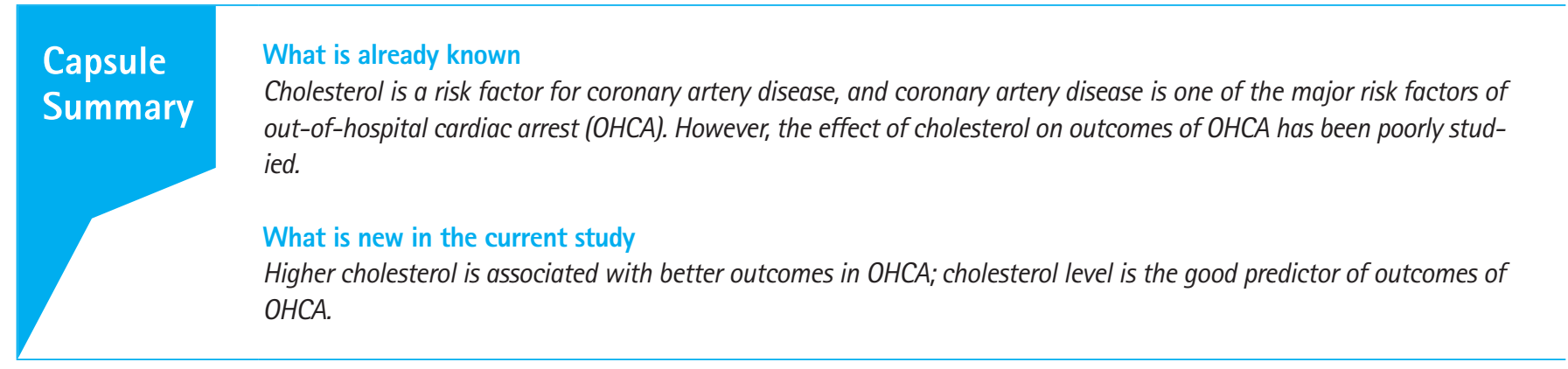

\section{INTRODUCTION}

Out-of-hospital cardiac arrest (OHCA) is the leading cause of death worldwide. OHCA occurs in 13 out of every 10,000 people in the United States (326,000 cases/yr), with a survival rate of 8\% when treated. ${ }^{1,2}$ The survival rate is low and the prognosis is often poor, despite intra-resuscitation and post-resuscitation efforts for OHCA. ${ }^{2}$ The burden of public medical treatment due to the occurrence of OHCA is increasing. ${ }^{3,4}$

Cholesterol is an alcohol with a steroid skeleton and is an essential substance that maintains the structural integrity and fluidity of cell membranes. ${ }^{5}$ It is also a precursor of steroid hormones, bile acid, vitamin $D$, as well as constituents of the cell membrane. ${ }^{6}$ Cholesterol levels are recommended to be below $200 \mathrm{mg} / \mathrm{dL}$ for normal adults, are considered borderline high between 200 and $239 \mathrm{mg} / \mathrm{dL}$ and high above $240 \mathrm{mg} / \mathrm{dL}^{7,8}$ Hypocholesterolemia refers to serum cholesterol levels less than $120 \mathrm{mg} / \mathrm{dL}$, concerning mostly those individuals in the 5th percentile of the distribution of normal adults. ${ }^{9}$

In general, higher cholesterol levels are a risk factor for coronary artery disease (CAD), and $\mathrm{CAD}$ is a major risk factor for $\mathrm{OH}-$ $C A .{ }^{10-14}$ However, the effects of cholesterol level on the outcomes of OHCA have not been extensively studied, apart from rat studies or a limited number of human studies. ${ }^{15-19}$ According to several studies, adverse events that cause severe damage to the human body, such as cerebral infarction, cerebral hemorrhage, major burns, surgery, and sepsis, show better outcomes in individuals with higher cholesterol levels. ${ }^{20-26}$

In this study we aimed to determine the association of cholesterol level with outcomes of OHCA.

\section{METHODS}

\section{Study design and setting}

This cross-sectional study used the Cardiac Arrest Pursuit Trial with Unique Registration and Epidemiologic Surveillance (CAP-
TURES) project database in Korea. Emergency medical technicians operate ambulances at the request of the dispatcher. If there is no physician stopping emergency treatment or declaring death online, cardiopulmonary resuscitation (CPR) continues, and the patient would be transferred to the emergency department (ED). EDs are divided into three levels, with more resources and facilities at levels 1 and 2, and resident emergency physicians present 24 hours a day, 365 days a year. Please refer to the reports for the characteristics of the emergency medical service (EMS) and emergency medical technicians, and the characteristics of the OHCA protocols and the EDs. ${ }^{27,28}$

The study was performed at 27 hospitals, where the 2010 CPR guidelines were generally accepted as a standard protocol, including hypothermia treatments. Standard advanced life support including airway management, chest compression, and circulatory support at the emergency room were used in each hospital. However, details of CPR drugs, fluid therapy, and ventilatory care modules were selected according to the physicians' preference. Hypothermia treatment followed the target temperature of $32^{\circ} \mathrm{C}$ to $34^{\circ} \mathrm{C}$ in the study period. The cooling methods, duration of initiation, maintenance and rewarming of cooling differed according to the hospital but generally adhered to the 2010 guidelines. Details of cooling methods were selected by hospital and the physicians' preference. EMS CPR was recommended by the national fire department on the basis of the EMS medical direction guideline.

\section{Study participants}

Patients were enrolled in this study from January to December 2014; the study comprised adults over 18 years of age transferred to the hospital by the EMS after cardiac arrest. Patients without a cardiac etiology or who had been transferred from another hospital were excluded; patients with unknown cholesterol levels and those with traumatic OHCA were excluded. 


\section{Data collection and protocols}

The CAPTURES project was designed to identify the risk factors for OHCA and their prognoses. This project was a hospital-based prospective cohort study conducted in 27 EDs from January to December 2014 (9 level one EDs and 18 level two EDs). Patients with OHCA of cardiac etiology having undergone resuscitation by the EMS and transportation to the ED were included in the study. Patients with terminal illness, pregnancy, requiring hospice care, homeless, and carrying 'Do Not Resuscitate' cards were excluded. The CAPTURES registry uses Utstein templates and laboratory tests to record social, physical, emotional, medical history, and outcomes from the EMS and ED. These data were collected by ED physicians through structured survey papers directly provided to the family, or by study coordinators from each ED reviewing medical records and investigating long-term outcomes over the telephone over 6 to 12 months. The collected data were inputted and transmitted to the central data server using EpiData ver. 3.1 (Filefacts, USA; http://www.filefacts.com) and was filtered using this data entry system. A quality management committee, consisting of emergency physicians, cardiologists and statisticians, trained all ED physicians and coordinators prior to the project and gave feedback to the coordinators every month.

\section{Measurement of variables}

The main exposure was total cholesterol (TC) level, which corresponded to the blood test value at the time of CPR recorded in the CAPTURES database. Cholesterol groups were defined according to TC levels as low TC $(0 \leq \mathrm{TC} \leq 119 \mathrm{mg} / \mathrm{dL})$, middle TC $(120 \leq$ TC $\leq 199 \mathrm{mg} / \mathrm{dL})$, and high TC ( $\geq 200 \mathrm{mg} / \mathrm{dL})$. The cut-off values followed the international guidelines. ${ }^{7-9}$

It was anticipated that fasting before the blood test would not significantly affect the test results. ${ }^{29}$ Patients with physician-diagnosed dyslipidemia or who were taking anti-hyperlipidemic drugs were included regardless. Confounders included age, sex, co-morbidities (hypertension and diabetes), Utstein factors (arrest location, witnessed, bystander CPR, and initial shockable rhythm), EMS factors (response time, scene time, and transport time), and serum laboratory factors (hemoglobin, albumin, and protein levels).

\section{Measurement of outcomes}

The primary endpoint was survival to discharge and the secondary endpoint was good cerebral performance category (CPC) level. Survival to discharge was defined as being alive and going home, or to a nursing home or extended care facility. ${ }^{30} \mathrm{CPC}$ is the gold standard for determining the neurological outcomes of cardiac arrest, and good CPC encompasses CPC1 and CPC2 patients. ${ }^{31}$

\section{Statistical analysis}

Demographic variables were described by the distribution of potential risk factors for outcomes between low TC, middle TC, and high TC. Categorical variables were compared using the chi-square test, and continuous variables were compared using the Wilcoxon rank-sum test.

A multivariable logistic regression analysis was performed to test the association between low TC, middle TC, and high TC groups and outcomes, adjusting for potential confounders such as age, sex, co-morbidities (hypertension and diabetes), Utstein factors (arrest location, witnessed, bystander CPR, and initial shockable rhythm), and EMS factors (response time, scene time, and transport time). Adjusted odds ratios (ORs) and 95\% confidence intervals (Cls) were calculated (reference: low TC). A multivariable logistic regression analysis was performed to test the association between shockable rhythm and the outcomes, adjusting for potential confounders to calculate adjusted ORs and 95\% Cls (reference: non-shockable rhythm).

Potential confounders were selected from the univariate analysis using $P<0.20$ level for a strong association. Some factors such as bystander CPR or witness which were already known to

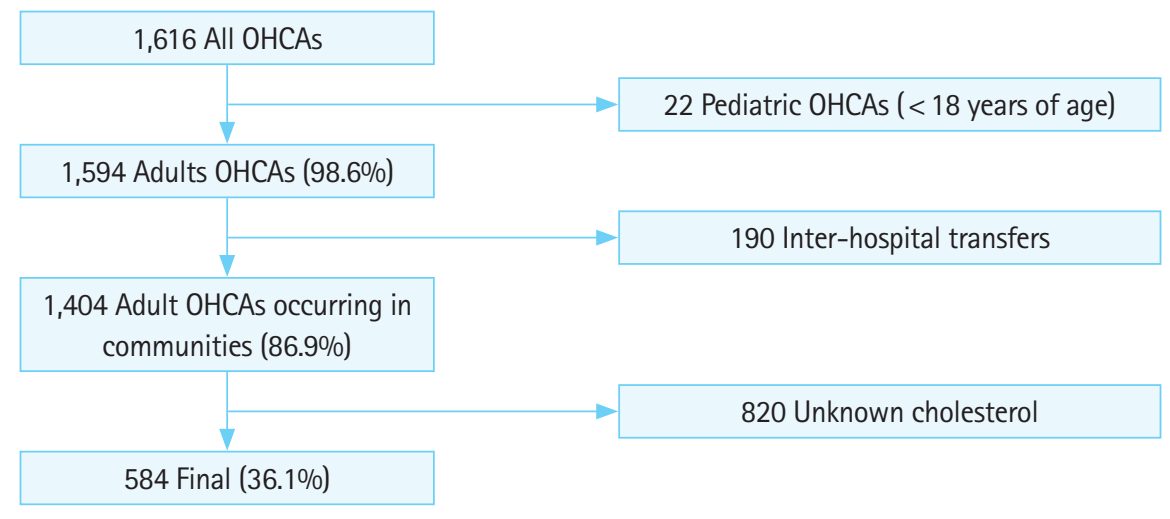

Fig. 1. Study population flow chart. OHCA, out-of-hospital cardiac arrest. 
be strongly associated with outcome were included even though the P-value was over 0.02 . We put the potential variables into the final multivariable logistic analysis model and tested the collinearity diagnostics among variables in particular laboratory results using a condition index of less than 20. The final model had no collinearity among variables. We tested the goodness-of-fit using the Hosmer-Lemeshow method in the final model and the level of fitness was acceptable when the Hosmer-Lemeshow-chi was less than 15 and P-value $>0.05$.

An interaction analysis was performed to compare the effect size of TC according to initial electrocardiogram (ECG) rhythm using the same model with adjustments for interaction terms (analysis based on TC group when initial ECG is shockacle or nonshockable), in addition to potential confounders in the above main analysis.

\section{Ethics statement}

The study complied with the tenets of the Declaration of Helsinki and the study protocol was approved by all institutional review boards of the 27 participating study institutions with a waiver of informed consent.

\section{RESULTS}

\section{Study population}

The total number of cases of OHCA available for this study was 1,616 and, of these, 584 were ultimately analyzed, after exclud-

Table 1. Characteristics and outcomes of the study population classified by total cholesterol level

\begin{tabular}{|c|c|c|c|c|c|}
\hline & Total & $\begin{array}{l}\text { Low } \\
\text { total cho- } \\
\text { lesterol }^{\mathrm{a})}\end{array}$ & $\begin{array}{l}\text { Middle } \\
\text { total choles- } \\
\text { terol }^{b)}\end{array}$ & $\begin{array}{c}\text { High } \\
\text { total cho- } \\
\text { lesterol }^{\mathrm{c}}\end{array}$ & P-value \\
\hline All & 584 (100) & 197 (100) & 322 (100) & $65(100)$ & \\
\hline Sex & & & & & 0.020 \\
\hline Male & 404 (69.2) & $125(63.5)$ & $226(70.2)$ & 53 (81.5) & \\
\hline Female & $180(30.8)$ & $72(36.5)$ & $96(29.8)$ & $12(18.5)$ & \\
\hline Age (yr) & & & & & $<0.001$ \\
\hline $18-54$ & $156(26.7)$ & $29(14.7)$ & $100(31.1)$ & 27 (41.5) & \\
\hline $55-74$ & 226 (38.7) & $68(34.5)$ & $132(41.0)$ & $26(40.0)$ & \\
\hline$\geq 75$ & 202 (34.6) & $100(50.8)$ & $90(28.0)$ & $12(18.5)$ & \\
\hline Median (IQR) & $58(49-70)$ & $75(66-82)$ & $63.5(53-76)$ & $58(49-70)$ & \\
\hline Diabetes & & & & & 0.001 \\
\hline No & $170(29.1)$ & 44 (22.3) & 102 (31.7) & $24(36.9)$ & \\
\hline Yes & $137(23.5)$ & 68 (34.5) & 61 (18.9) & 8 (12.3) & \\
\hline Unknown & $277(47.4)$ & 85 (43.1) & $159(49.4)$ & $33(50.8)$ & \\
\hline Hypertension & & & & & 0.003 \\
\hline No & $136(23.3)$ & 35 (17.8) & 79 (24.5) & 22 (33.8) & \\
\hline Yes & $217(37.2)$ & $90(45.7)$ & $114(35.4)$ & $13(20.0)$ & \\
\hline Unknown & 231 (39.6) & 72 (36.5) & $129(40.1)$ & 30 (46.2) & \\
\hline
\end{tabular}

(Continued to the next)
Table 1. Continued

\begin{tabular}{|c|c|c|c|c|c|}
\hline & Total & $\begin{array}{l}\text { Low } \\
\text { total cho- } \\
\text { lesterol }^{\text {a) }}\end{array}$ & $\begin{array}{l}\text { Middle } \\
\text { total choles- } \\
\text { terol }\end{array}$ & $\begin{array}{c}\text { High } \\
\text { total cho- } \\
\text { lesterol }^{\mathrm{c}}\end{array}$ & P-value \\
\hline \multicolumn{5}{|l|}{ Witness } & 0.995 \\
\hline No & $206(35.3)$ & $70(35.5)$ & $113(35.1)$ & $23(35.4)$ & \\
\hline Yes & $378(64.7)$ & $127(64.5)$ & $209(64.9)$ & $42(64.6)$ & \\
\hline \multicolumn{5}{|l|}{ Location } & $<0.001$ \\
\hline Private & $424(72.6)$ & $163(82.7)$ & $222(68.9)$ & $39(60.0)$ & \\
\hline Public & $160(27.4)$ & $34(17.3)$ & $100(31.1)$ & $26(40.0)$ & \\
\hline \multicolumn{5}{|l|}{ Bystander CPR } & 0.829 \\
\hline No & $334(57.2)$ & $116(58.9)$ & $182(56.5)$ & $36(55.4)$ & \\
\hline Yes & $250(42.8)$ & $81(41.1)$ & $140(43.5)$ & $29(44.6)$ & \\
\hline \multicolumn{5}{|l|}{ ECG at EMS } & $<0.001$ \\
\hline Non-shockable & 443 (75.9) & $174(88.3)$ & $229(71.1)$ & $40(61.5)$ & \\
\hline Shockable & $141(24.1)$ & $23(11.7)$ & 93 (28.9) & 25 (38.5) & \\
\hline \multicolumn{5}{|c|}{ Response time (min) } & 0.745 \\
\hline $0<\leq 4$ & $111(19.0)$ & $30(15.2)$ & $68(21.1)$ & $13(20.0)$ & \\
\hline $4<\leq 8$ & $305(52.2)$ & $105(53.3)$ & $167(51.9)$ & $33(50.8)$ & \\
\hline $8<\leq 12$ & $113(19.3)$ & $43(21.8)$ & $58(18.0)$ & $12(18.5)$ & \\
\hline$>12$ & $55(9.4)$ & $19(9.6)$ & $29(9.0)$ & 7 (10.8) & \\
\hline \multicolumn{5}{|l|}{ Scene time (min) } & 0.020 \\
\hline $0<\leq 4$ & $153(26.2)$ & $61(31.0)$ & $70(21.7)$ & $22(33.8)$ & \\
\hline $4<\leq 8$ & $202(34.6)$ & $58(29.4)$ & $117(36.3)$ & $27(41.5)$ & \\
\hline $8<\leq 12$ & $133(22.8)$ & 45 (22.8) & $75(23.3)$ & $13(20.0)$ & \\
\hline$>12$ & 96 (16.4) & 33 (16.8) & $60(18.6)$ & $3(4.6)$ & \\
\hline \multicolumn{5}{|c|}{ Transport time (min) } & 0.076 \\
\hline $0<\leq 4$ & $70(12.0)$ & $27(13.7)$ & $38(11.8)$ & $5(7.7)$ & \\
\hline $4<\leq 8$ & $205(35.1)$ & $65(33.0)$ & $119(37.0)$ & $21(32.3)$ & \\
\hline $8<\leq 12$ & $128(21.9)$ & 39 (19.8) & 65 (20.2) & $24(36.9)$ & \\
\hline$>12$ & $181(31.0)$ & 66 (33.5) & $100(31.1)$ & $15(23.1)$ & \\
\hline \multicolumn{5}{|c|}{ Hemoglobin (g/dL) } & $<0.001$ \\
\hline $0<\leq 10.3$ & $140(24.0)$ & $90(45.7)$ & $49(15.2)$ & $1(1.5)$ & \\
\hline $10.3<\leq 14.6$ & $297(50.9)$ & $90(45.7)$ & $175(54.3)$ & $32(49.2)$ & \\
\hline$>14.6$ & $147(25.2)$ & $17(8.6)$ & $98(30.4)$ & $32(49.2)$ & \\
\hline \multicolumn{5}{|l|}{ Protein $(\mathrm{g} / \mathrm{dL})$} & $<0.001$ \\
\hline $0<\leq 5.6$ & $138(23.6)$ & 78 (39.6) & $58(18.0)$ & $2(3.1)$ & \\
\hline $5.6<\leq 6.8$ & $287(49.1)$ & $87(44.2)$ & $173(53.7)$ & $27(41.5)$ & \\
\hline$>6.8$ & $159(27.2)$ & $32(16.2)$ & $91(28.3)$ & $36(55.4)$ & \\
\hline \multicolumn{5}{|l|}{ Albumin $(\mathrm{g} / \mathrm{dL})$} & $<0.001$ \\
\hline $0<\leq 3.0$ & $132(22.6)$ & $91(46.2)$ & $39(12.1)$ & $2(3.1)$ & \\
\hline $3.0<\leq 4.0$ & $295(50.5)$ & $92(46.7)$ & $180(55.9)$ & $23(35.4)$ & \\
\hline$>4.0$ & $157(26.9)$ & $14(7.1)$ & $103(32.0)$ & $40(61.5)$ & \\
\hline \multicolumn{6}{|l|}{ Outcomes } \\
\hline $\begin{array}{l}\text { Prehospital } \\
\text { ROSC }\end{array}$ & 61 (10.4) & $8(4.1)$ & 41 (12.7) & $12(18.5)$ & $<0.001$ \\
\hline $\begin{array}{l}\text { Survival to dis- } \\
\text { charge }\end{array}$ & 106 (18.2) & $18(9.1)$ & 71 (22.0) & 17 (26.2) & $<0.001$ \\
\hline $\begin{array}{l}\text { Good cerebral } \\
\text { performance } \\
\text { category }\end{array}$ & 70 (12.0) & $9(4.1)$ & $47(14.6)$ & 15 (23.1) & $<0.001$ \\
\hline
\end{tabular}

Values are presented as number (\%).

$I Q R$, interquartile range; $C P R$, cardio-pulmonary resuscitation; $E C G$, electrocardiogram; EMS, emergency medical services; ROSC, return of spontaneous circulation.

a) $0-119 \mathrm{mg} / \mathrm{dL}$. b) $120-199 \mathrm{mg} / \mathrm{dL}$. c) $200 \mathrm{mg} / \mathrm{dL}$ and higher. 
ing pediatric events $(n=22)$, inter-hospital transfers $(n=190)$ and cases with unknown cholesterol levels $(n=890)$ (Fig. 1). Patients with low, middle and high TC levels were 197, 322, and 65, respectively.

\section{Characteristics and outcomes of the study population}

Compared to low $\mathrm{TC}$, more patients survived to discharge from the middle TC and high TC groups (9.1\% vs. $22.0 \%$ and $26.2 \%$, respectively, $\mathrm{P}<0.001)$. Good CPC was also higher in the same order ( $4.1 \%$ vs. $14.6 \%$ and $23.1 \%$, respectively, $P<0.001$ ) (Table 1 ).

\section{Main analysis}

Multivariable logistic regression analysis on the outcomes of middle TC and high TC compared with low TC (Table 2) resulted in unadjusted ORs (95\% Cls) of 2.81 (1.62 to 4.88) and 3.52 (1.69 to 7.35) for survival to discharge, respectively, and 4.04 (1.87 to 8.74 ) and 7.09 (2.85 to 17.66 ) for good neurological recovery, respectively. TC, age, sex, hypertension, diabetes mellitus, witness, location, bystander cardiopulmonary resuscitation, response time, scene time, and transport time were set as variables, resulting in adjusted ORs ( $95 \% \mathrm{Cls}$ ) for middle TC and high TC compared with low TC of 1.97 (1.06 to 3.64) and 2.53 (1.08 to 5.92) for survival to discharge, respectively, and 2.53 (1.07 to 5.98$)$ and 4.73 (1.63 to 13.71) for good neurological recovery, respectively.

Due to the large effect of ECG at EMS, multivariable logistic regression analysis was performed, as well as interaction analysis for TC.

First, multivariable logistic regression analysis was performed for shockable rhythm compared with non-shockable rhythm (Table 3). Replacing the TC variable of Table 2 with the ECG at EMS variable, adjusted ORs (95\% Cls) were 7.65 (4.49 to 13.05) for survival to discharge and 17.32 (8.30 to 36.15$)$ for good neurological recovery.

Interaction analysis was performed on the outcomes between TC groups and initial ECG rhythm (Table 4). The adjusted ORs (95\% Cls) for shockable rhythm were 1.51 ( 0.85 to 2.68$)$ and 2.19 (1.05 to 4.56) for survival to discharge, for middle TC and high TC versus low TC, respectively, and 1.04 (0.57 to 1.91) and 2.25 (1.03 to

Table 2. Multivariable logistic regression analysis on outcomes by total cholesterol level

\begin{tabular}{|c|c|c|c|c|}
\hline & Total & Outcome & $\begin{array}{l}\text { Unadjusted odds ratio } \\
\text { (95\% confidence interval) }\end{array}$ & $\begin{array}{c}\text { Adjusted odds ratio } \\
\text { (95\% confidence interval) }\end{array}$ \\
\hline \multicolumn{5}{|l|}{ Survival to discharge } \\
\hline Low total cholesterola) & 197 & $18(9.1)$ & 1.00 & 1.00 \\
\hline Middle total cholesterol ${ }^{\text {b) }}$ & 322 & $71(22.0)$ & $2.81(1.62-4.88)$ & $1.97(1.06-3.64)$ \\
\hline High total cholesterol ${ }^{c}$ & 65 & $17(26.2)$ & $3.52(1.69-7.35)$ & $2.53(1.08-5.92)$ \\
\hline \multicolumn{5}{|l|}{ Good cerebral performance category } \\
\hline All & 582 & $70(12.0)$ & - & - \\
\hline Low total cholesterol ${ }^{\text {a) }}$ & 118 & $8(6.8)$ & 1.00 & 1.00 \\
\hline Middle total cholesterol $\left.{ }^{b}\right)$ & 333 & $47(14.1)$ & $4.04(1.87-8.74)$ & $2.53(1.07-5.98)$ \\
\hline High total cholesterol ${ }^{\mathrm{c})}$ & 100 & $15(15.0)$ & $7.09(2.85-17.66)$ & $4.73(1.63-13.71)$ \\
\hline
\end{tabular}

Values are presented as number or number (\%) unless otherwise indicated.

${ }^{a)} 0-119 \mathrm{mg} / \mathrm{dL} .{ }^{b)} 120-199 \mathrm{mg} / \mathrm{dL} .{ }^{\mathrm{c})} 200 \mathrm{mg} / \mathrm{dL}$ and higher.

Table 3. Multivariable logistic regression analysis on outcomes by electrocardiogram rhythm

\begin{tabular}{|c|c|c|c|c|}
\hline & Total & Outcome & $\begin{array}{l}\text { Unadjusted odds ratio } \\
\text { (95\% confidence interval) }\end{array}$ & $\begin{array}{c}\text { Adjusted odds ratio } \\
\text { (95\% confidence interval) }\end{array}$ \\
\hline \multicolumn{5}{|c|}{ Survival to discharge } \\
\hline Non-shockable & 443 & $36(8.1)$ & 1.00 & 1.00 \\
\hline Shockable & 141 & $70(49.6)$ & $11.14(6.93-17.91)$ & $7.65(4.49-13.05)$ \\
\hline \multicolumn{5}{|c|}{ Good cerebral performance category } \\
\hline Shockable & 141 & $58(41.1)$ & $25.10(12.91-48.77)$ & $17.32(8.30-36.15)$ \\
\hline
\end{tabular}

Values are presented as number or number (\%) unless otherwise indicated. 
Table 4. Interaction analysis on outcomes between the cholesterol group and the electrocardiogram rhythm group

\begin{tabular}{|c|c|c|}
\hline & $\begin{array}{l}\text { Non-shockable } \\
\text { adjusted odds ratio } \\
\text { (95\% confidence } \\
\text { interval) }\end{array}$ & $\begin{array}{l}\text { Shockable adjusted } \\
\text { odds ratio } \\
\text { (95\% confidence } \\
\text { interval) }\end{array}$ \\
\hline \multicolumn{3}{|l|}{ Survival to discharge } \\
\hline Low total cholestero| ${ }^{a)}$ & 1.00 & 1.00 \\
\hline Middle total cholesterol ${ }^{\text {b) }}$ & $1.23(0.82-1.84)$ & $1.51(0.85-2.68)$ \\
\hline High total cholesterol ${ }^{(c)}$ & $1.31(0.74-2.33)$ & $2.19(1.05-4.56)$ \\
\hline \multicolumn{3}{|c|}{ Good cerebral performance category } \\
\hline Low total cholesterola) & 1.00 & 1.00 \\
\hline Middle total cholesterol ${ }^{b)}$ & $0.90(0.54-1.51)$ & $1.04(0.57-1.91)$ \\
\hline High total cholesterol ${ }^{c)}$ & $1.69(0.85-3.36)$ & $2.25(1.03-4.87)$ \\
\hline
\end{tabular}

${ }^{\text {a) }} 0-119 \mathrm{mg} / \mathrm{dL}$. b) $120-199 \mathrm{mg} / \mathrm{dL}$. ${ }^{\mathrm{c}} 200 \mathrm{mg} / \mathrm{dL}$ and higher.

4.87) for good neurological recovery, for middle TC and high TC versus low $\mathrm{TC}$, respectively.

\section{DISCUSSION}

In this study, we found that the higher the TC levels the better the outcomes in OHCA; when TC levels were higher than $120 \mathrm{mg} /$ $\mathrm{dL}$, the outcomes were better than for cholesterol levels lower than $120 \mathrm{mg} / \mathrm{dL}$. The effect of initial ECG rhythm on the outcomes and results of the interaction analysis showed that the outcomes were better with respect to shockable rhythm for TC levels higher than $200 \mathrm{mg} / \mathrm{dL}$, compared to levels lower than 120 $\mathrm{mg} / \mathrm{dL}$. When the initial ECG rhythm was non-shockable, the pattern of outcomes changed with increasing cholesterol level, and the analysis was difficult due to the high mortality rate. Therefore, we analyzed shockable rhythms and found that outcomes were improved with increasing cholesterol level.

Some studies support these results. In humans, it has been shown that lowering cholesterol levels using drugs or food does not lower the mortality of sudden cardiac events and, in turn, cannot lower OHCA mortality. ${ }^{18,19}$ Studies in rats have shown that abundant cholesterol at the acute phase of cardiac arrest can help the heart withstand anoxic damage to cardiomyocytes. ${ }^{15-17}$

There are also studies on other diseases, such as cerebral infarction, in which higher cholesterol level reflected better outcomes, and lower cholesterol level reflected worse outcomes. ${ }^{20-22}$ Similar results were obtained for cerebral hemorrhage, major burns, surgery, and sepsis, which severely damage the human body. The reason is that lower cholesterol levels reflect greater amounts of inflammatory cytokines such as interleukin 6 and tumor necrosis factor $a$ and worse outcomes. ${ }^{23-26}$ The role of cholesterol (especially high-density lipoprotein cholesterol) is to bind to bacterial endotoxins (lipopolysaccharides) and neutralize them, thereby lowering the level of inflammatory cytokines and reducing the incidence of complications. ${ }^{32,33}$ These results were similar in older age and hospitalized patients. ${ }^{34-36}$

Studies on the factors that influence the outcomes of OHCA have been carried out in various fields until now. ${ }^{37}$ However, lowdensity lipoprotein cholesterol, a subtype of cholesterol, has been identified as a causative agent of coronary artery disease, and studies of how TC levels affect the outcomes of OHCA are lacking. ${ }^{5,38}$

This study potentially suffers from various limitations. First, since the CAPTURES database records only the state at discharge and does not include the duration of hospitalization, outcomes vary depending on duration. Thus, it is necessary to additionally confirm the outcomes at 6 months and 12 months post-discharge to improve the accuracy of the results. Second, this study was designed as a cross-sectional study, not an interventional trial, and many patients were excluded; as a result, there were not enough cases with hypercholesterolemia over $240 \mathrm{mg} / \mathrm{dL}$ in the guideline. Third, this study used measurements of TC determined via different laboratory methods, making it impossible to obtain uniform and accurate test samples across all hospitals; the uniformity and accuracy were also influenced by the different conditions, including fasting status, of the patients. ${ }^{39,40}$ Fourth, the excluded patients whose cholesterol levels were not measured comprised more than 50 percent (selection bias). If these patients were included in the analysis, the results could be different. Fifth, patients with prehospital return of spontaneous circulation also showed an increase in cholesterol levels, but it is hard to know how many of them were sustained return of spontaneous circulation and used by analysis. Finally, we did not measure the proportion of anti-lipid medications used by patients. This unmeasured bias could affect the results.

Cholesterol level is an important factor that affects the outcomes of OHCA, and cholesterol levels above $120 \mathrm{mg} / \mathrm{dL}$ are associated with better outcomes. This study was designed to uncover the role of TC level, which is routinely examined by physicians when cardiac arrest occurs in the emergency room, but has been thought of as carrying little importance in predicting outcomes of OHCA. We, on the other hand, believe that it will be very helpful in predicting outcomes of OHCA.

Based on the above studies, in order to conclude that higher cholesterol level has a positive effect on the outcomes of OHCA, we need to see how cholesterol affects the incidence of OHCA. Of course, it will also be necessary to increase the number of patients by widening the period and target. From this study, we just found an association between cholesterol level and OHCA outcomes. We expect that this study result will motivate and encourage fur- 
ther research on the subgroups of cholesterol relevant to outcomes such as low-density lipoprotein and high-density lipoprotein cholesterol, molecular functions, and peptides related with CPR outcomes.

\section{CONFLICT OF INTEREST}

No potential conflict of interest relevant to this article was reported.

\section{ACKNOWLEDGMENTS}

This study was supported by the Wonkwang University in 2018. Original data collection was financially supported by the Korea Centers for Disease Control and Prevention of the Republic of Korea government (2013-2014) (grant no. 2013E3300500/2014E3300100).

\section{REFERENCES}

1. Harris KM, Creswell $L L$, Haas $T S$, et al. Death and cardiac arrest in U.S. Triathlon participants, 1985 to 2016: a case series. Ann Intern Med 2017;167:529-35.

2. McNally $B$, Robb R, Mehta M, et al. Out-of-hospital cardiac arrest surveillance: Cardiac Arrest Registry to Enhance Survival (CARES), United States, October 1, 2005: December 31, 2010. MMWR Surveill Summ 2011;60:1-19.

3. Writing Group Members, Mozaffarian D, Benjamin EJ, et al. Heart disease and stroke statistics-2016 update: a report from the American heart association. Circulation 2016;133:e38360.

4. Deo R, Albert CM. Epidemiology and genetics of sudden cardiac death. Circulation 2012;125:620-37.

5. Cox RA, Garcia-Palmieri MR. Cholesterol, triglycerides, and associated lipoproteins. In: Walker HK, Hall WD, Hurst JW, editors. Clinical methods: the history, physical, and laboratory examinations. 3rd ed. Boston: Butterworths; 1990. p. 153-60.

6. Cerqueira NM, Oliveira EF, Gesto DS, et al. Cholesterol biosynthesis: a mechanistic overview. Biochemistry 2016;55:5483506.

7. Thelle DS. Epidemiology of hypercholesterolemia and European management guidelines. Cardiology 1990;77 Suppl 4:2-7.

8. Lloyd-Jones DM, Hong Y, Labarthe D, et al. Defining and setting national goals for cardiovascular health promotion and disease reduction: the American Heart Association's strategic Impact Goal through 2020 and beyond. Circulation 2010;121: 586-613.

9. Levesque $H$, Gancel $A$, Pertuet $S$, Czernichow $P$, Courtois $H$.
Hypocholesterolemia: prevalence, diagnostic and prognostic value. Study in a department of internal medicine. Presse Med 1991;20:1935-8.

10. Ripley DP, Motwani M, Plein S, Greenwood JP. Established and emerging cardiovascular magnetic resonance techniques for the assessment of stable coronary heart disease and acute coronary syndromes. Quant Imaging Med Surg 2014;4:33044.

11. Jousilahti P, Vartiainen E, Tuomilehto J, Puska P. Sex, age, cardiovascular risk factors, and coronary heart disease: a prospective follow-up study of 14786 middle-aged men and women in Finland. Circulation 1999;99:1165-72.

12. Thorgeirsson G, Thorgeirsson G, Sigvaldason $H$, Witteman J. Risk factors for out-of-hospital cardiac arrest: the Reykjavik Study. Eur Heart J 2005;26:1499-505.

13. Kannel WB, Gagnon DR, Cupples LA. Epidemiology of sudden coronary death: population at risk. Can J Cardiol 1990;6:43944.

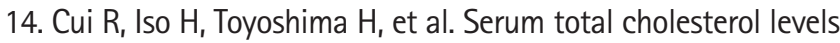
and risk of mortality from stroke and coronary heart disease in Japanese: the JACC study. Atherosclerosis 2007;194:41520.

15. Bastiaanse EM, van der Valk-Kokshoorn $\sqcup$, Egas-Kenniphaas $J M$, Atsma DE, van der Laarse A. The effect of sarcolemmal cholesterol content on the tolerance to anoxia in cardiomyocyte cultures. J Mol Cell Cardiol 1994;26:639-48.

16. Das M, Gherghiceanu M, Lekli I, Mukherjee S, Popescu LM, Das DK. Essential role of lipid raft in ischemic preconditioning. Cell Physiol Biochem 2008;21:325-34.

17. See Hoe LE, Schilling JM, Tarbit E, et al. Sarcolemmal cholesterol and caveolin-3 dependence of cardiac function, ischemic tolerance, and opioidergic cardioprotection. Am J Physiol Heart Circ Physiol 2014;307:H895-903.

18. de Lorgeril M, Salen P. Cholesterol lowering and mortality: time for a new paradigm? Nutr Metab Cardiovasc Dis 2006; 16:387-90.

19. de Lorgeril M, Salen P. Cholesterol lowering, sudden cardiac death and mortality. Scand Cardiovasc J 2008;42:264-7.

20. Lai YT, Hsieh CL, Lee HP, Pan SL. Are higher total serum cholesterol levels associated with better long-term motor function after ischemic stroke? Nutr Neurosci 2012;15:239-43.

21. Vauthey $C$, de Freitas GR, van Melle G, Devuyst G, Bogousslavsky J. Better outcome after stroke with higher serum cholesterol levels. Neurology 2000;54:1944-9.

22. Zuliani G, Cherubini A, Atti AR, et al. Low cholesterol levels are associated with short-term mortality in older patients with ischemic stroke. J Gerontol A Biol Sci Med Sci 2004;59: 
293-7.

23. Roquer J, Rodriguez Campello A, Gomis $M$, et al. Serum lipid levels and in-hospital mortality in patients with intracerebral hemorrhage. Neurology 2005;65:1198-202.

24. Vanni HE, Gordon BR, Levine DM, et al. Cholesterol and interleukin- 6 concentrations relate to outcomes in burn-injured patients. J Burn Care Rehabil 2003;24:133-41.

25. Gordon BR, Parker TS, Levine DM, et al. Relationship of hypolipidemia to cytokine concentrations and outcomes in critically ill surgical patients. Crit Care Med 2001;29:1563-8.

26. Fraunberger P, Pilz G, Cremer P, Werdan K, Walli AK. Association of serum tumor necrosis factor levels with decrease of cholesterol during septic shock. Shock 1998;10:359-63.

27. Ro YS, Shin SD, Song KJ, et al. A trend in epidemiology and outcomes of out-of-hospital cardiac arrest by urbanization level: a nationwide observational study from 2006 to 2010 in South Korea. Resuscitation 2013;84:547-57.

28. Ro YS, Shin SD, Song KJ, et al. Interaction effects between hypothermia and diabetes mellitus on survival outcomes after out-of-hospital cardiac arrest. Resuscitation 2015;90:35-41.

29. Naugler C, Sidhu D. Break the fast? Update on patient preparation for cholesterol testing. Can Fam Physician 2014;60: 895-7.

30. Eisenberg MS, Cummins RO, Damon S, Larsen MP, Hearne TR. Survival rates from out-of-hospital cardiac arrest: recommendations for uniform definitions and data to report. Ann Emerg Med 1990;19:1249-59.

31. Raina KD, Callaway C, Rittenberger JC, Holm MB. Neurological and functional status following cardiac arrest: method and tool utility. Resuscitation 2008;79:249-56.

32. Gallay P, Heumann D, Le Roy D, Barras C, Glauser MP. Lipo- polysaccharide-binding protein as a major plasma protein responsible for endotoxemic shock. Proc Natl Acad Sci U S A 1993;90:9935-8.

33. Cavaillon JM, Fitting C, Haeffner-Cavaillon N, Kirsch SJ, Warren HS. Cytokine response by monocytes and macrophages to free and lipoprotein-bound lipopolysaccharide. Infect Immun 1990;58:2375-82.

34. Liang Y, Vetrano DL, Qiu C. Serum total cholesterol and risk of cardiovascular and non-cardiovascular mortality in old age: a population-based study. BMC Geriatr 2017;17:294.

35. Weverling-Rijnsburger AW, Blauw GJ, Lagaay AM, Knook DL, Meinders $A E$, Westendorp RG. Total cholesterol and risk of mortality in the oldest old. Lancet 1997;350:1119-23.

36. Windler E, Ewers-Grabow U, Thiery J, Walli A, Seidel D, Greten $H$. The prognostic value of hypocholesterolemia in hospitalized patients. Clin Investig 1994;72:939-43.

37. Peberdy MA, Callaway CW, Neumar RW, et al. Part 9: postcardiac arrest care: 2010 American Heart Association Guidelines for Cardiopulmonary Resuscitation and Emergency Cardiovascular Care. Circulation 2010;122:S768-86.

38. Stone NJ, Robinson JG, Lichtenstein AH, et al. 2013 ACC/AHA guideline on the treatment of blood cholesterol to reduce atherosclerotic cardiovascular risk in adults: a report of the American College of Cardiology/American Heart Association Task Force on Practice Guidelines. Circulation 2014;129:S145.

39. Gruchot M, Graeter T, Oeztuerk S, et al. Fasting time and lipid parameters: association with hepatic steatosis: data from a random population sample. Lipids Health Dis 2014;13:18.

40. Nigam PK. Serum lipid profile: fasting or non-fasting? Indian J Clin Biochem 2011;26:96-7. 